УДК 332.132

\author{
Козлов Александр Николаевич \\ Амурский государственный университет, \\ г. Благовещенск, Россия \\ E-mail: kozlov1951@yandex.ru \\ Kozlov Alexander Nikolaevich \\ Amur State University, \\ Blagoveshchensk, Russia \\ E-mail: kozlov1951@yandex.ru \\ Мирошниченко Татьяна Александровна \\ Амурский государственный университет, \\ г. Благовещенск, Россия \\ E-mail: tatyanamirosch@mail.ru \\ Miroshnichenko Tatiana Alexandrovna \\ Amur State University, \\ Blagoveshchensk, Russia \\ E-mail: tatyanamirosch@mail.ru \\ Козлов Виталий Александрович \\ АО «Дальневосточная распределительная сетевая компания», \\ г. Благовещенск, Россия \\ E-mail: spr4@drsk.ru \\ Kozlov Vitaly Alexandrovich \\ Far Eastern Distribution Grid Company JSC, \\ Blagoveshchensk, Russia \\ E-mail: spr4@drsk.ru \\ Ротачева Алла Георгиевна \\ Амурский государственный университет, \\ г. Благовещенск, Россия \\ E-mail: rotachevaalla@mail.ru \\ Rotacheva Alla Georgievna \\ Amur State University, \\ Blagoveshchensk, Russia \\ E-mail: rotachevaalla@mail.ru
}

РОЛЬ ТОПЛИВНО-ЭНЕРГЕТИЧЕСКОГО КОМПЛЕКСА В РАЗВИТИИ ЖИЛИЩНО-КОММУНАЛЬНОГО ХОЗЯЙСТВА АМУРСКОЙ ОБЛАСТИ

\title{
ROLE OF THE FUEL AND ENERGY COMPLEX IN THE DEVELOPMENT OF HOUSING
} AND UTILITIES IN THE AMUR REGION

Аннотация. При анализе роли ТЭК в развитии жслищно-коммунального сектора Амурской области акцент был сделан на обеспеченности населения электроэнергией. Выявлено, что потребление электроэнергии населением растет, несмотря на снижение его численности. Ли- 
деры по потреблению электроэнергии на дуиу населения - городские округа, а такље северные и ряд южных муниципальных районов.

Abstract. When analyzing the role of the fuel and energy complex in the development of the housing and communal sector of the Amur Region, the emphasis was placed on the provision of the population with electricity. It was revealed that the consumption of electricity by the population is growing, despite the decrease in the number of Amur residents. The leaders in per capita electricity consumption are urban districts, as well as northern and a number of southern municipal districts.

Ключевые слова: потребление электроэнергии населением, среднедушевое потребление, картосхема.

Key words: electricity consumption by the population, per capita consumption, schematic map.

DOI: $10.22250 /$ jasu.95.13

Роль топливно-энергетического комплекса в развитии жилищно-коммунального сектора складывается из нескольких составляющих. Прежде всего это степень обеспеченности населения ресурсами ТЭК - топливом, теплом, электроэнергией. Кроме того, имеет значение стоимость этих ресурсов для населения - тарифы.

По Амурской области в структуре потребительских расходов домашних хозяйств оплата коммунальных услуг составила в 2016 г. 14\%. Самый низкий показатель за десять лет был зафиксирован в 2008 г. и составил 9,3 \% (рис. 1) [1]. В масштабах Российской Федерации аналогичный показатель в течение последних пяти лет изменялся незначительно - с 8,4\% в 2010 г. до 11,3\% в 2016 г. [4].

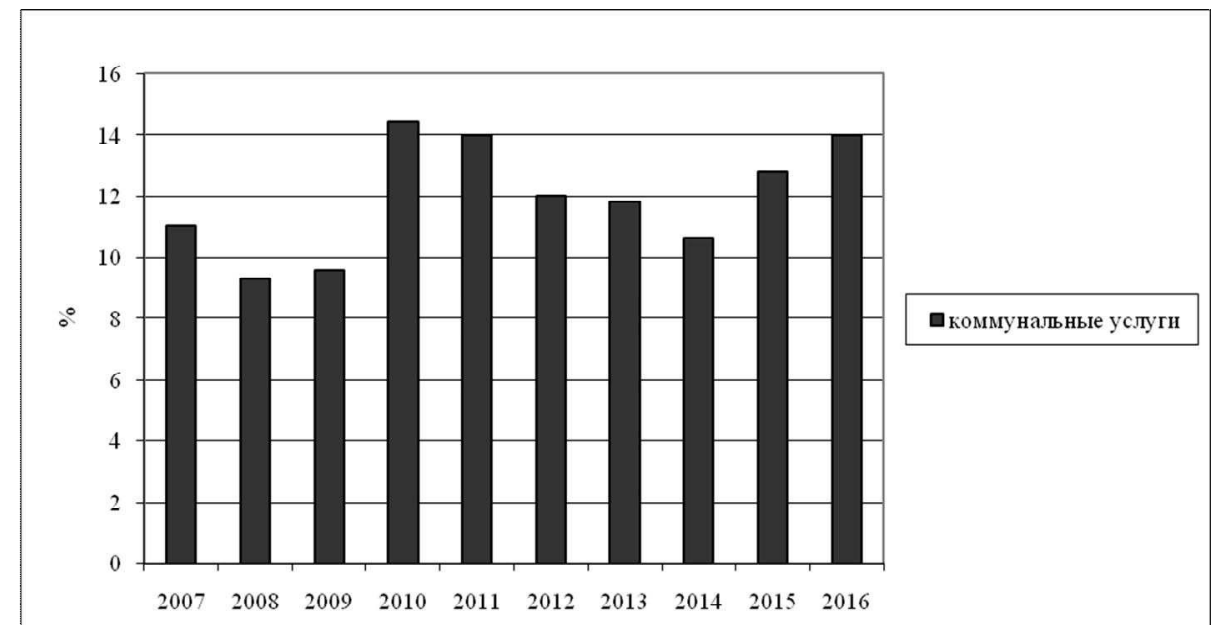

Puc. 1. Доля коммунальных услуг в общем объеме потребительских расходов населения Амурской области (составлено по: [2, 3]).

В структуре потребительских расходов, в зависимости от уровня ресурсов домохозяйств, доля оплаты коммунальных услуг в 2016 г. составляла от 13\% (в домохозяйствах с наибольшими доходами) до 22,7\% (в домохозяйствах с наименьшими доходами) [1].

Отношение электроэнергии, потребленной населением, к общему объему электропотребления варьирует в зависимости от исследуемого объекта. Мы сравнили данные показатели, взятые для Российской Федерации в целом, для Дальневосточного федерального округа и для Амурской области. Сравнение проводилось по данным 2007 г. и 2016 г., в итоге оказалось, что в ДФО и в России в целом доля электропотребления населения возросла на 2-3,5\%, а по Амурской области снизилась на 17,5\% (рис. 2).

Для более объективной оценки ситуации электропотребление на душу населения было рассмотрено в динамике за соответствующий период (рис. 3). 


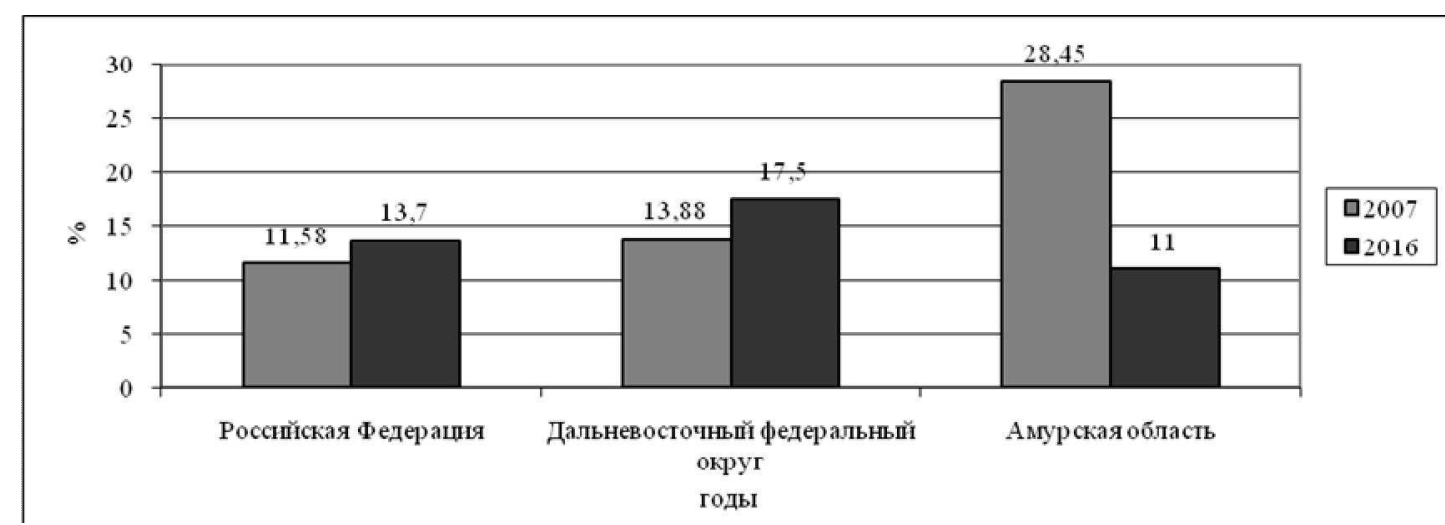

Puc. 2. Доля электропотребления населением в общем объеме электропотребления, в \% [5].

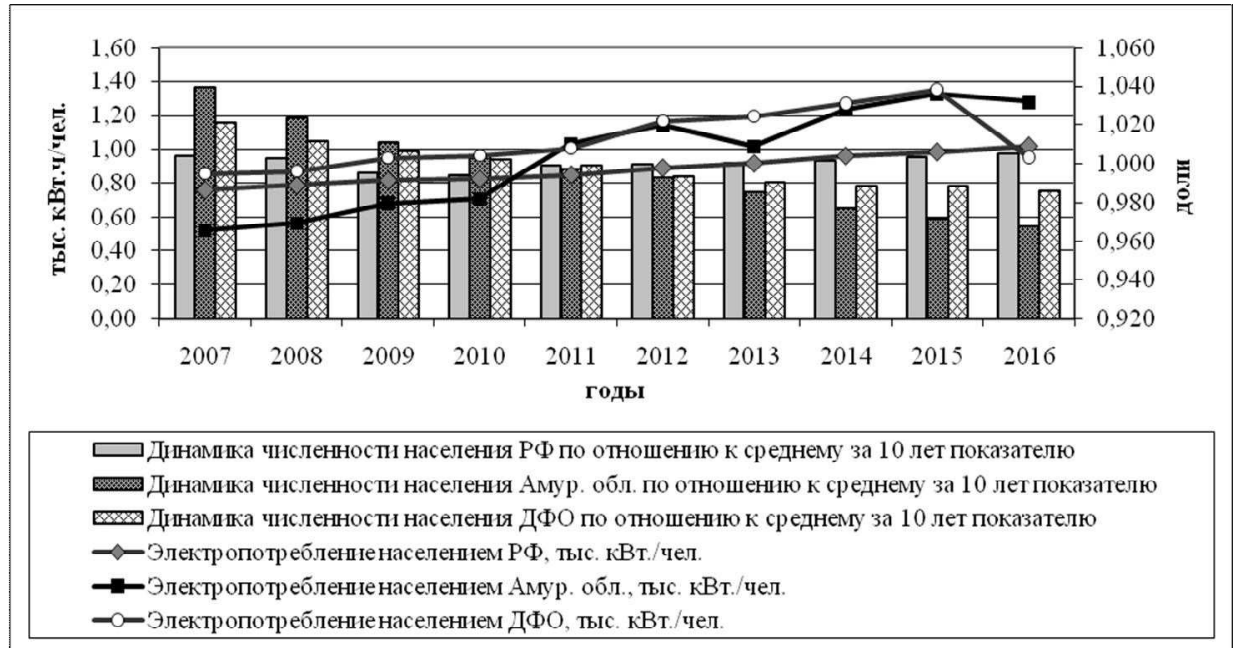

Рис. 3. Среднедушевое потребление электроэнергии населением РФ, ДФО и Амурской области (в тыс. кВт./чел.) и динамика численности населения РФ, ДФО и Амурской области (по отношению к среднему за 10 лет показателю) [5].

Исходя из данных, приведенных на рис. 2 и 3, можно сделать следующие выводы.

В России численность населения за последние 10 лет была относительно стабильной, с некоторой тенденцией к росту, проявившейся в последние 6 лет. Этим в определенной степени можно объяснить рост электропотребления населением, а кроме того, нельзя не учитывать увеличение применения электротехники в быту (с 2007 г. по 2016 г. количество электротехнических средств, используемых в быту домохозяйствами, возросло на 8,5\%) [4].

В Дальневосточном федеральном округе наблюдается иная картина - при снижении численности населения наблюдается рост душевого электропотребления, что объясняется также ростом применения электротехники в быту, причем даже в большей степени, чем в среднем по России.

В Амурской области, как уже отмечалось, в отличие от двух предыдущих уровней, произошло снижение доли потребления электроэнергии населением в общем объеме электропотребления (рис. 2).

Это связано в первую очередь со строительством на территории области ряда крупных энергоемких объектов и ростом электропотребления в производственной и транспортной сфере, а также со снижением численности населения. Но, с другой стороны, согласно рис. 3, в Амурской области при значительных темпах снижения численности его жителей (в среднем на 7 тыс. человек в год) наблюдается рост электропотребления на душу населения, в среднем на 0,1 тыс. кВт/чел. в год (в России аналогичный показатель составил 0,03 тыс. кВт/чел. в год). Объяснить сложившуюся ситуацию можно ростом числа электротехнических приборов, используемых населением в быту и повседневной жизни (за 10 лет этот показатель составил 10,2\%), увеличением численности населения, не заре- 
гистрированного по месту жительства, а также износом сетей теплоснабжения и компенсацией недостатка тепла за счет электрообогревателей [1].

При построении картосхемы по электропотреблению населением был использован средневзвешенный минимальный норматив электропотребления по России, рассчитанный на основе «Методических рекомендаций по расчету и сбору платежей населения за жилищно-коммунальные услуги», разработанных ООО «НКЦ ЖКХ» [6]. В соответствии с нормативами он составляет 520 кВт·ч на человека в год, и с 2003 г. этот критерий не менялся. Данный показатель в качестве базовой величины был соотнесен с показателями электропотребления в быту на человека в год (тыс. кВт·ч на чел.) по всем муниципальным образованиям Амурской области. В результате получены искомые показатели, которые были нанесены на картосхему (рис. 4).

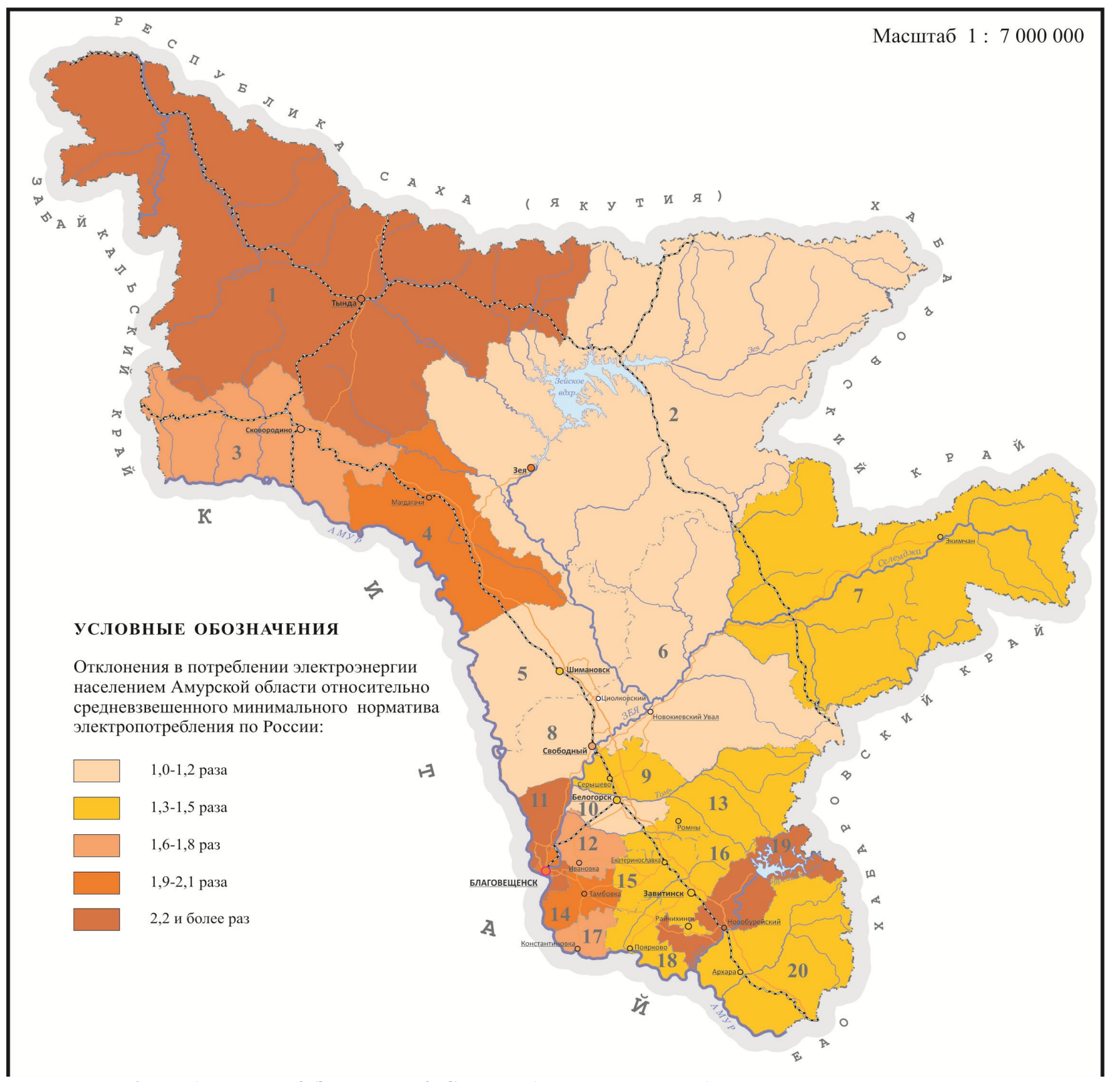

Районы: 1.Тындинский; 2.Зейский; 3.Сковородинский; 4.Магдагачинский; 5.Шимановский;

6.Мазановский; 7.Селемджинский; 8.Свободненский; 9.Серышевский; 10.Белогорский;

11.Благовещенский; 12.Ивановский; 13.Ромненский; 14.Тамбовский; 15.Октябрьский;

16.Завитинский; 17.Константиновский; 18.Михайловский; 19.Бурейский; 20.Архаринский.

Рuc. 4. Картосхема муниципальных образований Амурской области

по электропотреблению населением [5]. 
Следует отметить, что расчеты проводились на базе данных по Амурской области за 2008 г. и уточнялись по 2014 г. Полученный средний по области показатель электропотребления в быту на душу населения оказался в 1,66 раза выше средневзвешенного минимального норматива по России. Лидерами по потреблению электроэнергии на душу населения в области оказались г. Тында, а также районы: Тындинский, Благовещенский и Бурейский. Минимальные значения данного показателя выявлены в Белогорском, Зейском, Мазановском, Свободненском и Шимановском районах.

В значительной степени сложившуюся ситуацию можно объяснить уровнем обеспеченности населения различными бытовыми электрическими приборами, а их количество напрямую связано с уровнем благосостояния. Для определения уровня благосостояния территориальным органом Федеральной службы государственной статистики по Амурской области была проведена группировка городских округов и муниципальных районов по размерам начисленной заработной платы в расчете на одного работника за 2014 г. [3]. Лидерами по этому показателю оказались Тындинский (50,9 тыс. руб.), Сковородинский (45 тыс. руб.), Магдагачинский (40,6 тыс. руб.) и Бурейский (37 тыс. руб.) районы, а также городские округа Тында (48,6 тыс. руб.), Белогорск, Зея и Благовещенск (около 37 тыс. руб.). При этом средний показатель по области составил 32,4 тыс. руб. В группу с минимальными размерами начисленной заработной платы в расчете на одного работника (меньше 25 тыс. руб.) попали Константиновский, Мазановский, Тамбовский, Ромненский и Белогорский районы. Остальные города и районы области оказались в средней группе с, показателями от 25 до 36 тыс. руб. [3]. Как следует из данных, приведенных на рис. 4, муниципальные районы с более высокими заработными платами, действительно, в большинстве своем лидируют по электропотреблению на душу населения.

Интересной для анализа является доля потребления электроэнергии населением в общем объеме электропотребления по городским округам и муниципальным районам. Поскольку в Амурской области в настоящее время крупные энергоемкие объекты строятся и только собираются выходить на проектную мощность (за исключением самих объектов генерации), значительная доля электропотребления приходится именно на население. В среднем по области этот показатель в 2007 г. составлял $28,5 \%$ от общего потребления электроэнергии по муниципальным образованиям, а в 2016 г. снизился до 11\%, однако по некоторым районам - Архаринский, Завитинский, Ромненский, а также в пгт Прогресс он превышает уровень в 50\%.

\footnotetext{
1. Амурский статистический ежегодник 2017. Статистический сборник. - Благовещенск: Амурстат, 2017. $472 \mathrm{c}$. $620 \mathrm{c}$.

2. Амурский статистический ежегодник 2009. Статистический сборник. - Благовещенск: Амурстат, 2009. -

3. Амурский статистический ежегодник 2015. - Благовещенск: Амурстат, 2015. - 564 с.

4. Российский статистический ежегодник. 2017. Статистический сборник. - М.: Росстат, 2017. - 686 с.

5. Мирошниченко, Т.А., Козлов, А.Н. Территориальная структура топливно-энергетического комплекса Амурской области: современное состояние и перспективы развития. - Благовещенск: Изд-во АмГУ, 2020. $189 \mathrm{c.}$

6. Методические рекомендации по расчету и сбору платежей населения за жилищно-коммунальные услуги. - М., 2003. - ООО «НКЦ ЖКХ». - URL: https://meganorm.ru/Index2/1/4294815/4294815109.htm (дата обращения 24.08.2011).
} 